\title{
Kinh tế Việt Nam - Thăng tràm và đột phá được Nxb Chính trị Quốc gia Sự thật tái bản
}

\author{
Vương Quân Hoàng \\ Hà Nội, ngày 28 tháng 7 năm 2021 \\ OSF Preprints; doi: 10.31219/osf.io/cek9n
}

Sau hơn 12 năm lưu hành, tháng 7-2021, Nhà xuất bản Chính trị Quốc gia Sự thật đã cho tái bản cuốn sách Kinh tế Việt Nam - Thăng trầm và đột phá [1]. Đây là lần in lại đầu tiên của cuốn sách tại đúng nơi khai sinh nguyên thủy, năm 2009 [2].

(Trước đây, đã từng có hai lần tái bản vào các năm 2009, 2010, và đều do Nxb Tri Thức thực hiện. Các lần in này sách đều có bìa mềm, 'paperback [pbk])

Hình ảnh bìa cuốn sách lần in thứ hai của Nxb Chính trị Quốc gia Sự thật.

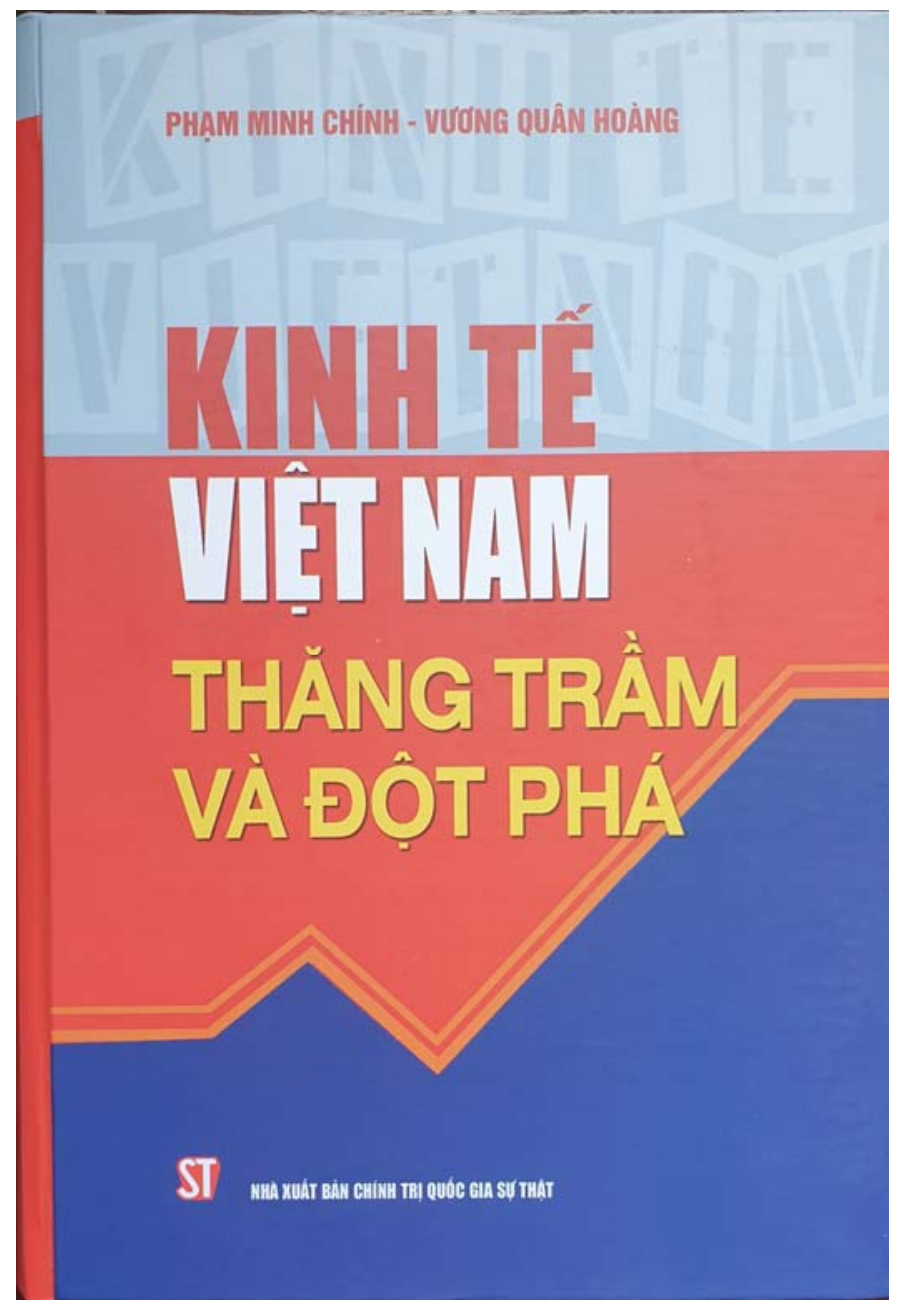


Bìa trước Kinh tế Việt Nam: Thăng trầm và đột phá, bản in tháng 7 năm 2021, Nxb Chính trị Quốc gia Sự thật.

Cuốn sách có số ISBN-13 là: 978-604-57-6947-8.

Hình ảnh hai trang đầu cuốn sách với thông tin lưu trữ thư viện.

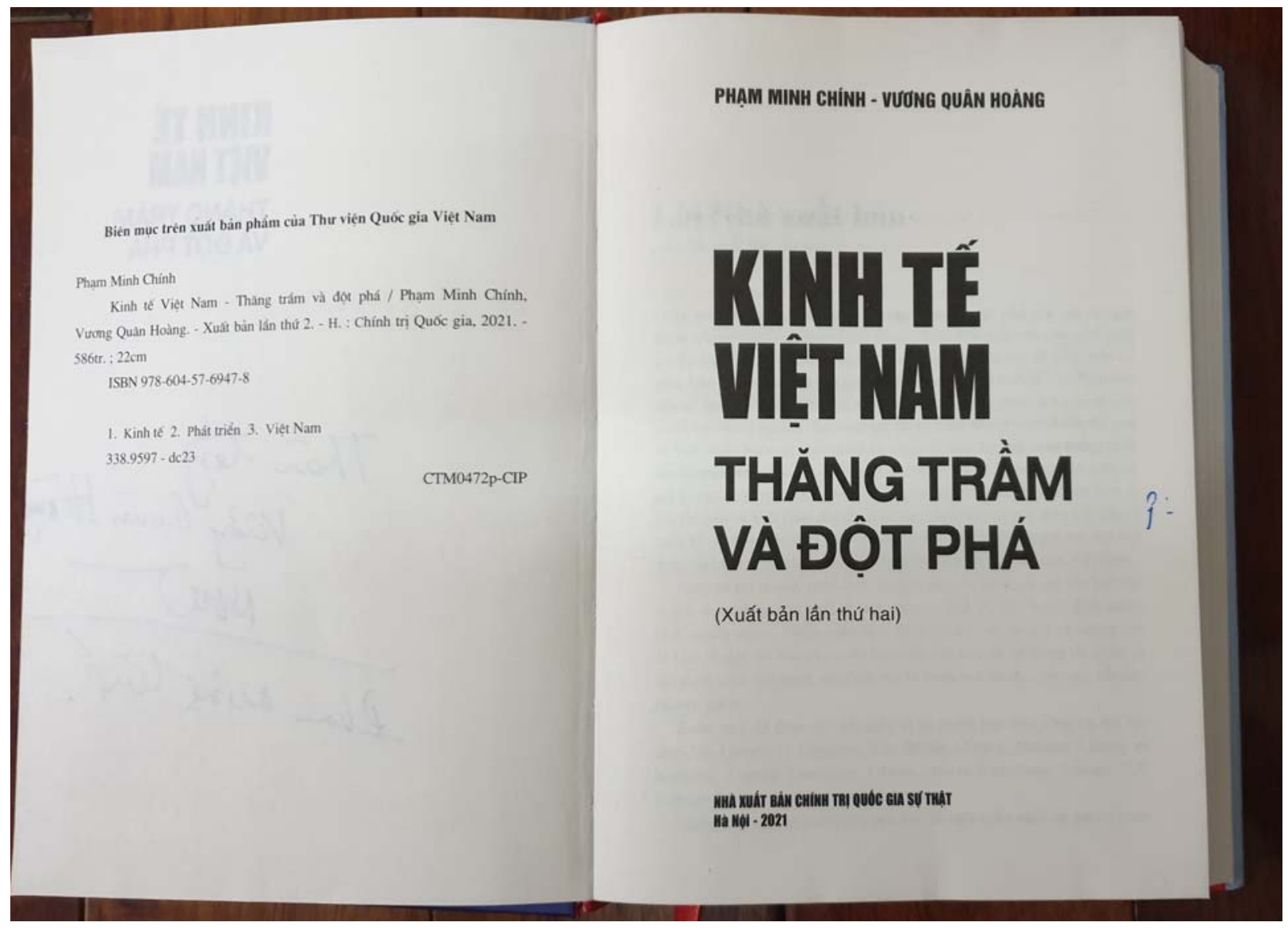

Trang bên trái là thông tin dùng cho biên mục lưu trữ Thư viện Quốc gia

Lần phát hành này, cuốn sách được in với loại giây in chất lượng tốt, xét theo định hướng bảo vệ môi trường. Đây là loại giấy xốp, nhẹ, xuất xứ Phần Lan. Màu giấy hơi vàng chứ không trắng như giấy Bãi Bằng trước kia. Trước kia, tôi nhớ là sau biên tập, sách mang đi in tại Nhà in Tiến Bộ. Tuy vậy, lần này Nhà xuất bản đã có cơ sở in ấn trực thuộc, Nhà in Sự Thật.

Có thể nói, lần in này giúp cho thấy việc ứng dụng tiến bộ công nghệ thông tin vượt trội của Nxb Chính trị Quốc gia Sự thật (khi trước là Nxb Chính trị Quốc gia, với logo ST nằm phía trước, một thay đổi về nhận diện hình ảnh truyền thống). 
Là một nhà nghiên cứu, một tác giả bắt đầu xuất bản từ năm 1996 (tới nay đã $1 / 4$ thế kỷ cầm bút và xuất bản), niềm vui nhìn thấy sách tái bản đối với cá nhân tôi là một niềm vui đặc biệt, khó bút nào tả xiết.

Lại cũng có chút suy ngẫm về thời gian của bản thân. Tôi chợt nhận ra, chỉ một lần thế này nữa thôi, là mình đã ngoài 60 tuổi, "lục thập nhi nhĩ thuận". Kể như mà tới lúc đó vẫn còn có dịp thấy cuốn sách được tái bản và đón nhận nữa thì thực sự là niềm vui quá đỗi lớn lao.

Để có được niềm vui này, cá nhân tôi hết sức biết ơn đồng tác giả senior, PGS. TS.

Phạm Minh Chính, và Giám đốc - Tổng biên tập Nxb PGS. TS. Phạm Minh Tuấn, cùng với đội ngũ biên tập viên của Nxb đã làm việc không ngừng nghỉ và trách nhiệm rất cao.

\section{Tài liệu tham khảo:}

[1] Phạm Minh Chính, Vương Quân Hoàng. (2021). Kinh tế Việt Nam: Thăng trầm và đột phá. Nxb Chính trị Quốc gia Sự thật, Hà Nội. [Lần in thứ hai]

[2] Phạm Minh Chính, Vương Quân Hoàng. (2009). Kinh tế Việt Nam: Thăng trầm và đột phá. Nxb Chính trị Quốc gia, Hà Nội. 